VICTOR AUILO HAIKAL

\title{
DIREITO À IDENTIDADE NA SOCIEDADE DA INFORMAÇÃO
}

\author{
DISSERTAÇÃO - MESTRADO \\ Orientador: Prof. Associado Dr. Antonio Carlos Morato
}

UNIVERSIDADE DE SÃO PAULO

FACULDADE DE DIREITO

São Paulo

2019 

VICTOR AUILO HAIKAL

\section{DIREITO À IDENTIDADE NA SOCIEDADE DA INFORMAÇÃO}

Dissertação apresentada à Banca Examinadora do Programa de Pós-Graduação em Direito da Faculdade de Direito da Universidade de São Paulo, como exigência parcial para obtenção do título de Mestre em Direito, na área de concentração de Direito Civil, sob a orientação do Professor Associado Dr. Antonio Carlos Morato.

UNIVERSIDADE DE SÃO PAULO

FACULDADE DE DIREITO

São Paulo

2019 


\section{Catalogação na Publicação}

Serviço de Processos Técnicos da Biblioteca da

Faculdade de Direito da Universidade de São Paulo

Haikal, Victor Auilo

Direito à identidade na Sociedade da Informação. -- São Paulo, 2019.

$373 \mathrm{p}$.

Dissertação (Mestrado) - Programa de Pós-Graduação em Direito, Faculdade de Direito, Universidade de São Paulo, São Paulo, 2019.

Orientador: Antonio Carlos Morato. 
BANCA EXAMINADORA:

Orientador:

Professor Associado Dr. Antonio Carlos Morato - Presidente

Prof. Dr.

Instituição:

Julgamento:

Prof. Dr.

Instituição:

Julgamento:

Prof. Dr.

Instituição:

Julgamento: 



\section{SUMÁRIO}

1. INTRODUÇÃO 13

2. COMPREENSÃO DO OBJETO DE ESTUDO E SUA COMPLEXIDADE 15

2.1 - Enfoques filosóficos essenciais 15

2.2 - Breve abordagem das ciências psicológicas $\quad 18$

2.3 - Contribuições da Sociologia 24

2.4 - Acepção jurídica do direito à identidade 28

3 - DOS DIREITOS DE PERSONALIDADE - GÊNERO DO QUAL A IDENTIDADE É ESPÉCIE

3.1 - Breve resgate histórico da compreensão dos direitos de personalidade e sua previsão jurídica 33

3.1.1 - Países de tradição romano-germânica 36

3.1.2 - Países de tradição consuetudinária (Common Law) 43

3.1.3 - Ponto de chegada: Transição ao século XX 46

3.2 - Conceito do direito geral de personalidade, o objeto tutelado juridicamente e suas $\begin{array}{ll}\text { características } & 50\end{array}$

3.3 - Direitos de personalidade aplicados à pessoa jurídica 59

3.4 - Histórico do reconhecimento ao direito à identidade 63

3.4.1 - Evolução jurisprudencial italiana $\quad 64$

3.4.2 - Aplicabilidade do instituto na Alemanha $\quad 70$

3.4.3 - Contexto jurídico Françês $\quad 75$

3.4.4 - Evolução em Portugal $\quad 80$

3.4.5 - Na experiência jurídica dos Estados Unidos da América 85

$\begin{array}{ll}3.4 .6 \text { - Tratamento na Inglaterra } & 90\end{array}$

3.5 - O instituto da identidade pessoal no direito brasileiro 95

4. DIREITO À IDENTIDADE - INSTITUTOS ELEMENTARES 100

4.1 - Nome como parte do direito de identidade e não como dever de identificação $\quad 100$

4.1.1 - Nome da pessoa jurídica, firma, nome comercial e empresarial 109

4.1.2 - Institutos semelhantes: Pseudônimos, Vocatório e Heterônimos 115 
4.1.3 - Das possibilidades de mudança do nome na Sociedade da Informação

4.1.4 - Tutela do direito à identidade pela proteção do nome e formas semelhantes de identificação pessoal

4.1.5 - Do fim do direito à identidade pessoal

4.2 - Biometria como identidade física da pessoa: Imagem, voz e outros fenômenos envolvendo o corpo humano

4.2.1 - Tutela da identidade corpórea da pessoa

4.2.2 - Questão de ordem: Disposição do próprio corpo como busca pela plenitude da identidade pessoal

175

4.3 - Liberdade de informação e formação cultural no desenvolvimento da própria personalidade

4.3.1 - Tutela ao direito de liberdade de informação e formação cultural

4.4 - A verdade como identidade social moral da pessoa

4.4.1 - Tutela do direito à identidade social

4.5 - Identidade conferida pelos sinais distintivos no contexto econômico

201

4.5.1 - Das marcas

201

4.5.2 - Outros institutos distintivos: Títulos de estabelecimentos, a insígnia, sinais de propaganda, nomes de domínio e endereços particularizados em domínio de terceiros

4.5.3 - Solução de conflitos sobre o direito de detenção aos signos distintivos

4.5.4 - Tutela do direito à identidade pela preservação dos signos distintivos, garantia de seu exercício exclusivo e coibição da concorrência desleal

5.1. Linhas essenciais sobre a Sociedade da Informação

5.1.1. Sociedade em Rede - Interconectividade e reflexos na percepção do espaço tempo para a formação da identidade

5.1.2. Surgimento do Prosumer e sua consolidação como padrão cultural na Sociedade da Informação - Rapidez na consolidação como paradigma de identidade

5.1.3. Convergência proporcionando acesso imediato a informações, pessoas e comércio conforme o tempo escolhido pelo usuário - instantaneidade 
5.1.4. Do amplo acesso a informações à demanda específica alterando a dinâmica da sociedade - Openness com gratuidade - Sensação de abundância

5.2.5. A mudança acelerada e liquidez nas relações sociais

5.2.6. Ascensão da individualidade no compartilhamento do que se registra - apego à persistência das memórias

5.2.7. Colaboração - O poder da sociedade interligada

5.2 - Personalidade digital ou eletrônica

5.2.1 - Considerações de Lawrence Solum

5.2.2 - Considerações de David Gunkel:

5.2.3 - Sophia e a esperada humanização da inteligência artificial

5.2.4 - Posição do autor: Desnecessidade de atribuição de personalidade eletrônica para solução jurídica no Ordenamento

5.3.3 - Risco de anonimato pelo tratamento legal inadequado de registros de acesso a aplicações de internet - Falta de armazenamento das portas lógicas de conexão 287

5.3.4 - Usurpação do Trade Dress e de palavras-chaves em motores de busca 294

5.3.5 - O nome de domínio e seu registro abusivo 298

5.4 - Preservação da identidade pessoal nos sistemas de informação: 311

5.4.1 - A proteção de dados pessoais 311

5.4 .2 - Remoção de conteúdos pulverizados 326

5.5 - Bodyhacking 333

6- CONCLUSÕES 338

7. REFERÊNCIAS BIBLIOGRÁFICAS 345

7.1. OBRAS JURÍDICAS 345

7.2. OBRAS GERAIS E DE OUTRAS ÁREAS DO CONHECIMENTO 361 



\section{RESUMO}

A presente dissertação avalia o direito à identidade pessoal, assentando o resultado da pesquisa acerca de sua origem histórica, científica e jurídica, sendo espécie dos direitos da personalidade que possuem direta relação com a compreensão do homem como objeto central do direito e ponderando sobre as diversas manifestações do instituto, que possuem reflexos tanto no campo particular quanto no econômico, cuja leitura é feita à lume de casos recentes.

Também, a identidade pessoal foi analisada consoante o estado da técnica dos Sistemas de Informação no contexto histórico que também recebe tal nomenclatura, A Sociedade da Informação, sendo avaliados institutos jurídicos próprios à espécie ou os já tradicionais sob a perspectiva das aplicações de internet e de comportamentos pós-modernos.

Palavras-chave: Direitos de personalidade; Direito à identidade; Sociedade da Informação; Direito Digital; Personalidade Eletrônica 


\begin{abstract}
The present work assesses the right to personal identity, exposing the research results amongst its historical, scientific and legal origins, which composes the repertoire of so called personality rights and have straight connection the human being condition as the main subject of legal protection, also, pondering about the many projections of such legal institute, that reflects in both personal life and economic environments under recent legal precedents.
\end{abstract}

Indeed, the personal identity was assessed according to Information Systems' state of the technique in which historical context receives the same denomination, the Information Society, and impended the study of legal institutes proper to such epoch and the traditional ones under the internet application perspective and post-modern human behavior.

Keywords: Personality Rights; Right to personal identity; Information Society; Digital Law; Electronic Personality 


\section{INTRODUÇÃO}

O tema escolhido visa analisar as formas de manifestação do direito de identidade no essencialmente no âmbito do Direito Privado com releitura aplicada nas situações, contextos pós-modernos e atos jurídicos praticados na Sociedade da Informação, além daqueles compreendidos especialmente em meios e aplicações digitais ${ }^{1}$, em que há as mais diversas condutas e interações em plataformas ou dispositivos informatizados com reflexo no mundo jurídico.

A utilização da Internet como meio principal para conexão e comunicação entre pessoas e pessoas e instituições é fenômeno cada vez mais assente na Era da Informação ${ }^{2}$, em que é possível interagirem de onde quer que estejam e a qualquer hora, criando cenário em que as informações podem ser acessadas, salvas, enviadas, debatidas, absorvidas e registradas, além de acentuar a sensação de liberdade pela amplificação das potências da pessoa ${ }^{3}$.

Tal facilidade na troca de informações se dá especialmente pela formatação da Internet pela chamada versão $2.0^{4}$, em que não somente os usuários trocam informações com os sítios ou aplicações programados e disponibilizados a todos, mas, possuem seu reduto digital, de modo a fixar a importância de participação, colaboração e convivência na rede, produzindo e divulgando informações e conteúdos em vez de somente consumir.

\footnotetext{
${ }^{1}$ Assim compreendidas as aplicações de internet, definidas pelo artigo 5o, VII da Lei $\mathrm{n}^{\mathrm{o}} 12.965$ de 2014 e demais que podem, ou não, utilizar redes de informação para operar.

${ }^{2}$ Este paradigma foi descrito por Manuel Castells como Sociedade em Rede "as an historical trend, dominant functions and processes in the Information Age are increasingly organized around networks. Networks constitute the new social morphology of our societies, and the diffusion of networking logic substantially modifies the operation and outcomes in processes of production, experience, power, and culture. While the networking form of social organization has existed in other times and spaces, the new information technology paradigm provides the material basis for its pervasive expansion throughout the entire social structure. Furthermore, I would argue that this networking logic induces a social determination of a higher level than that of the specific social interests expressed through the networks: the power of flows takes precedence over the flows of power." In The information age: economy, society and culture. The rise of the network society. 2 ed. Oxford: Blackwell Publishing, 2010, Edição Kindle, p. 500.
}

${ }^{3}$ VALACICH, Joe; SCHNEIDER, Cristoph. Information Systems Today: Managing the Digital World. Nova Jersey: Pearson, 2012, p.7.

${ }^{4}$ O'REILly, Tim. What Is Web 2.0: Design Patterns and Business Models for the Next Generation of Software. Communications \& Strategies, n. 65, 2007. Disponível em < https://mpra.ub.unimuenchen.de/4578/1/MPRA_paper_4578.pdf > p. 19. Acesso em 17 jan 2019 
De tal sorte, esta facilidade na troca de dados e informações entre os usuários da Internet gera inseguranças jurídicas em razão da dificuldade de o Direito acompanhar a evolução da técnica, haja vista que a normatização legal e interpretação sistemática do Ordenamento Jurídico levam certo tempo para maturarem certos fatos em comparação com as constantes inovações impostas, havendo, portanto, determinado lapso temporal para que os operadores do Direito absorvam as mudanças no tecido social que o avanço tecnológico impõe.

Sob este panorama, analisar-se-á o instituto do direito à identidade, delimitando seu significado científico, origens e compreendendo como se deu a proteção jurídica do instituto e qual seu tratamento atual pela legislação e jurisprudência, e qual o impacto em situações jurídicas impulsionadas pela versatilidade que os meios digitais proporcionam.

Por conseguinte, é tarefa do presente estudo elencar e avaliar novos institutos jurídicos e releitura de diversos outros já tradicionais a partir do uso de Sistemas de Informação ${ }^{5}$ vinculados ao direito à identidade pessoal sob lume do avanço da técnica, dentre os quais serão examinadas amiúde a identidade digital e outras formas de individualização e identificação das pessoas, do desenvolvimento dinâmico de sua identidade, além de examinar o tema inovador da personalidade eletrônica ${ }^{6}$.

Impossível deixar de cuidar dos procedimentos e cautelas que devem ser aplicados na utilização das tecnologias de modo a assegurar o exercício e proteção dos direitos ligados à identidade, com base no estado da arte da técnica e na legislação em vigor acerca do tema.

\footnotetext{
5 Assim considerados aqueles formados por pessoas, hardware, software, dados, redes, políticas e procedimentos.

${ }^{6}$ Report with recommendations to the Commission on Civil Law Rules on Robotics (2015/2103(INL)), 27 Jan 2017. Disponível em < http://www.europarl.europa.eu/sides/getDoc.do?pubRef=-//EP//TEXT+REPORT+A8-

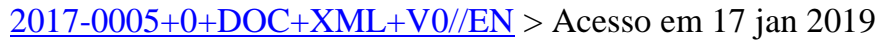




\section{6 - CONCLUSÕES}

Como resultado da pesquisa realizada, foi possível concluir:

- Que o direito à identidade como instituto próprio para estudo foi reconhecido no sistema Romano-Germânico a partir da evolução das ciências psicossociais, cujos primeiros traços tiveram origem entre a última década do séc. XIX e a primeira metade do séc. XX, em que se percebem as primeiras incidências históricas em países que sofreram com regimes ditatoriais, pois a jurisprudência Italiana e Alemã foram pioneiras no pós-guerra e Portugal em seu texto Constitucional que sucedeu o regime de Salazar, ou seja, como resposta para assegurar os direitos civis.

Não obstante, a jurisprudência dos Estados Unidos da América decidiu em 1890 situação que feria a verità de uma pessoa, ou seja, um dos aspectos elementares do direito à identidade pessoal, caso acompanhado de decisões anteriores mesmo à Segunda Guerra Mundial.

Com o sistema jurídico aberto para o reconhecimento dos direitos de personalidade pela conjugação das garantias fundamentais na Constituição Federal de 1998 com o texto do atual Código Civil se facilitou a incorporação do instituto no Direito Brasileiro, muito embora a doutrina já houvesse reconhecido sua existência, ainda que de modo precípuo.

- Que o nome não deve ser considerado como elemento de mera identificação registral da pessoa, mas como elemento primordial do exercício de ser, de viver com dignidade, estando em paz consigo mesma, uma vez que é o principal meio pelo qual é essencialmente reconhecida pela sociedade, tendo seu reconhecimento como direito elevado o valor que representa na vida do titular.

Se constatou, não raro, que o princípio de imutabilidade do nome pode mais prejudicar o titular por limitar o exercício regular do direito ao nome, notadamente nos casos de divergência da identidade de sexo, gênero, afinidade familiar ou motivo outro qualquer que comprometa o próprio apreço, em que o Poder Judiciário não 
considera ou compreende que o nome não é a única forma de se identificar uma pessoa e que os pedidos para retificação do nome dizem respeito, primordialmente, ao titular e não ao sistema público de identificação, que podem ser solucionados por meio de expedição de ofícios ou alteração direta em sistemas que poderiam ser integrados para facilitar o manejo de tais dados.

Ou seja, se o titular for privado de determinar qual seria a forma adequada de ser identificado por seu nome, qual a real utilidade do instituto?

Como sistema mais inclusivo, o Reino Unido estabeleceu o procedimento em sede notarial para a alteração do sexo e nome das pessoas que assim desejarem depois da condenação na Corte Europeia de Direitos Humanos em 2002.

A possibilidade do uso do nome social é saída digna para que a pessoa consiga atender parte de seus anseios, todavia, deve lhe ser garantida a satisfação pessoal de pertencimento ao constatar que seus assentos e documentos civis estão em consonância com sua identidade.

- Que a proteção dos aspectos individualizadores do corpo poderá sofrer mudanças em futuro próximo em razão do avanço das técnicas que envolvem a genética, seja para aumentar a efetividade do combate à prática de crimes ou da livre disposição a partir dos titulares que desejam instalar dispositivos tecnológicos subcutâneos para melhorar a experiência de autenticação em serviços ou incrementar alguma atividade corpórea.

Também, se ressalta a ilegalidade da imposição no uso desta tecnologia pelo empregador para fins de autenticação no local de trabalho pois o titular não deve ser compelido a se submeter à introdução de determinado material em seu organismo cujos riscos se desconhecem em contrapartida da perda das condições para próprio sustento.

- Que a garantia da liberdade de acesso à informação e formação do repertório intelectual e cultural é indispensável para que haja desenvolvimento adequado da identidade pessoal, o que não dispensa a adequada instrução e conscientização das 
pessoas acerca da gravidade do desrespeito cometido a partir de atos de discriminação, tão presentes na sociedade e em evidência nas aplicações digitais.

Respeitando as opiniões em sentido diverso, merece reparo a prática reiterada de intromissão do Estado para submeter a pessoa que possui determinada convicção religiosa a proceder de modo contrário ao que entende como essencial para manter a própria dignidade.

Como bem pontuado pela reflexão proposta pelo Ministro Luiz Roberto Barroso, de que vale o direito à vida de uma pessoa se ela poderá significar o fardo de carregar determinada circunstância como indigna perante seus pares.

Sob tal dilema normativo, é razoável que o Estado respeite o desejo do titular desde que haja manifestação livre de vícios sobre o que escolhe para si em situações que constem conflitos jurídicos de tal espécie, pois, novamente, é a real interessada na tutela de condução da própria vida é a própria pessoa.

Tal disposição também envolve o direito ao conhecimento da identidade genética, em casos que o titular é adotado ou foi gerado a partir de produção heteróloga, este último caso com a particularidade de dissenso entre a doutrina especializada e a disposição corrente de ética médica que prega a garantia de anonimato entre quem dá o material genético e quem o recebe ou é gerado a partir do procedimento, o que demandará esforços do Poder Judiciário para pacificar a divergência.

- Que a proteção da verdade social é imperiosa, pois seu comprometimento abala o resultado do desenvolvimento pessoal da própria identidade e que dele exigiu esforços diuturnos.

Tentativas espúrias de sensacionalismo e as chamadas 'fake news' vem sendo reiteradamente disseminadas no contexto da pós-modernidade e devem ser coibidas com rigor exemplar.

Não obstante, quando o afronte à verdade dos fatos é perfectbilizado, somente a indenização pode não ser suficiente, pois, conforme a lucidez de Carlos Alberto 
Bittar ao ensinar que "a opinião pública é muito sensível a notícias negativas", até a confiança ser reestabelecida pode ser exigido certo tempo para que o senso comum abdique da contaminação ilegítima da reputação do titular.

Assim, a reparação dos danos por meio de desagravo deve ser imposta ao ofensor, pois é legítimo que busque reabilitar a vítima no menor tempo possível a despeito do reconhecimento pessoal por terceiros, no intento de restaurar o status quo ante, muito embora se sabe que é impossível, mas, tal prática ajuda a atenuar a reprovação pública que foi imposta.

Vale dizer, também, que ao propagar a verdade o sujeito disponha incontinenti de salvo conduto para que haja a diminuição e desprezo de terceiros a seu bel-prazer, pois o erro cometido não autoriza o achincalhamento e exposição ao desprezo, uma vez que a dignidade da pessoa existe e deve ser respeitada ainda que seu titular tenha praticado de atos desonrosos.

- Que, tão importante quanto o nome para fins distintivos, a marca e signos afins desempenham papel importante na distinção da pessoa e suas atividades econômicas desenvolvidas no mercado, "os nomes mágicos" pelas lições de Denis Borges Barbosa, que demandam proteção jurídica pela incessante tentativa do maior ganho com o menor esforço por parte de usurpadores e falsificadores, desde a época Romana.

Decerto, a evolução da técnica e das maneiras de tráfico social também impulsionou a criatividade para se praticar a concorrência parasitária, em o uso de motor de busca visando produtos ou serviços do concorrente acabará por trazer visibilidade e benefícios mercantis para o usurpador, ou ainda, de se fazer parecer tanto com o concorrente pela apropriação de sua identidade visual a ponto de criar confusões e desvio de clientela, o que implica no dever de indenizar sem a comprovação detida dos prejuízos praticados ante a gravidade do ilícito e dos reflexos negativos na sociedade.

Ou ainda, de práticas espúrias de registro de domínio disponível na internet para posterior venda a quem realmente se interessa por ele, com base no critério de 
relevância econômica da identidade, podendo coincidir o nome de domínio com a marca, nome comercial ou forma de distinção outra com o endereço que foi requerido com propósito de revenda, o que é considerado ato ilícito e impõe a transferência compulsória de titularidade de uso para o interessado.

- Que o contexto tecnológico presente na Sociedade da Informação preocupa os operadores do direito pelas mudanças rápidas e seguidas de alguns paradigmas sociais e impõe a necessidade de antecipação de algumas situações para melhor conduzir os cuidados legais diante do cenário de inovação constante.

Com vistas a assegurar a possibilidade de reparação civil dos danos causados por veículos autônomos, robôs cuidadores ou médicos, drones e outras espécies de dispositivos com inteligência artificial aplicada, o Parlamento Europeu aventou possibilidade de atribuição de personalidade eletrônica para tais robôs, o que não foi encorajado por Parecer específico produzido para tal órgão e, como foi possível concluir, além de não solucionar as questões jurídicas propostas, não seria dotada da melhor razão jurídica em virtude da espécie.

Robôs não necessitam de personalidade jurídica para bem cumprir as funções e declinadas por seu controlador, proprietário, possuidor ou usuário e, caso fosse atribuído tal predicado, poderia haver direto conflito de interesses na longevidade dos robôs e preservação do meio ambiente, o que contraria todo o propósito de se adotar tal tecnologia. Em vez de auxiliar o homem e a humanidade criaria novos celeumas.

- Que a despeito da utilização vulgar das expressões 'personalidade digital' ou 'personalidade eletrônica', se demonstrou que se trata da identidade digital, prolongamento da identidade da pessoa nos Sistemas de Informação e que não se confunde com o identificador digital, recurso tecnológico voltado para autenticação do usuário e que compõe o conjunto da identidade digital, quando aplicável

- Que existe insegurança jurídica para a vítima de atos ilícitos praticados na internet no processo de investigação do ofensor, que impossibilita a descoberta de sua real identidade para que sejam promovidas as medidas judiciais próprias à espécie, 
Isso porque o entendimento judicial predominante no Tribunal de Justiça do Estado de São Paulo decide, no mais das vezes, pela não obrigatoriedade do fornecimento das portas lógicas de conexão ou do não-cabimento de sua entrega ao interessado declinando tal ônus somente ao provedor de conexão, o que possibilita a manifestação de pensamento mediante anonimato por vias indiretas, o que é vedado pela Constituição Federal.

- Que em razão do aumento do armazenamento de dados pessoais pelas empresas provedoras de aplicações de internet e a partir do tratamento desses ativos se denota a capacidade de se preverem as escolhas da pessoa ou de direcionar mensagem individualizada a partir do conhecimento do profiling do usuário com alto grau de acerto é indispensável que existam comandos de proteção de dados pessoais visando à segurança e transparência, além de serem respeitados os limites concedidos para tal atividade, sob pena de abuso de direito e violação incontinenti do direito à identidade do titular, que é protegida pela privacidade.

Embora a legislação brasileira específica sobre a matéria somente entrará em pleno vigor e efeito em 15 de agosto de 2020, já há dispositivos que o titular pode se valer para que seus anseios em sede de autodeterminação informativa sejam respeitados, sobretudo nas razões contidas no Código de Defesa do Consumidor e Marco Civil da Internet à luz da Cláusula Geral de Privacidade constante da Constituição Federal e da Cláusula Geral de Proteção aos Direitos da Personalidade do Código Civil.

Sob a égide de tais dispositivos, será considerado ato ilícito a abertura de perfil ou registro em aplicações de internet não solicitada pelo titular sem que haja sua comunicação, de modo que não fique alijado de controlar a disposição de seus dados por terceiros.

- Quando há a violação do direito à identidade de modo agudo, com a pulverização do conteúdo dentre as diversas aplicações de internet, será possível ao titular utilizar técnicas de forense computacional para barrar o compartilhamento ou reenvio do material que já tiver sido considerado ilícito pelo Poder Judiciário, pela norma aberta presente no Marco Civil da Internet e pela garantia de processo informático da função 
hash baseada em algoritmos confiáveis sobre os arquivos que contém o material violador.

Também, é lícito ao titular que exija das aplicações de internet o uso de mecanismos que já utilizarem para fins de mapeamento digital de conteúdos para fins de proteção a direitos autorais para a proteção dos direitos de personalidade como medida da melhor aplicação do direito para mitigar os danos que terceiros praticam a partir das plataformas correspondentes.

- Por fim, os titulares não devem ser compelidos a inserirem dispositivos eletrônicos em seu corpo para obterem acesso a produtos ou serviços, dada a proibição da venda casada no direito brasileiro e pela aplicação do princípio da precaução, diante dos riscos desconhecidos da novel experiência de integração homem-computador.

Ainda mais sensível será a imposição realizada por empregador, pois o trabalhador não terá escolha entre optar a se expor a risco não sabido ou comprometer o sustento próprio ou de sua família, sobretudo pelo risco de vigilância ou rastreamento fora do horário de expediente, que violaria incontinenti o direito de privacidade.

No mais, não deve ser vedado ao usuário realizar as modificações no próprio corpo que somente lhe digam respeito, por mais peculiares que possam parecer, em homenagem ao princípio da autodeterminação corporal, integrante do direito à identidade. 


\section{REFERÊNCIAS BIBLIOGRÁFICAS}

\subsection{OBRAS JURÍDICAS}

\section{LIVROS}

ALEXY, Robert. Teoria dos direitos fundamentais. 5ed. Trad. Virgílio Afonso da Silva. São Paulo: Malheiros, 2008.

ALVES, Alexandre Ferreira de Assumpção. A pessoa jurídica e os direitos da personalidade. Rio de Janeiro: Renovar, 1998

AMARAL, Francisco. Direito Civil. Introdução. 7ed. rev. mod. e aumentada. Rio de Janeiro: Renovar, 2008

ASCARELLI, Tullio. Teoria de la concorrenza e dei beni immateriali. 3ed. Milão: Giuffrè, 1960

ASCENSÃO, José de Oliveira. Direito civil. vol. 1. Introdução. As pessoas. Os bens. 3ed. São Paulo: Saraiva, 2010.

Direito da internet e da sociedade da informação. Rio de Janeiro: Forense, 2002

BARBOSA, Denis Borges. Do trade dress e suas relações com a significação secundária.

Nov. 2011. Disponível em < http://www.denisbarbosa.addr.com/arquivos/200/propriedade/trade_dress.pdf $>$ Acesso em 17 jan 2019

. Uma introdução à propriedade intelectual. 2 ed. rev. atual. São Paulo: Lumen Juris, 2010

BARBOSA, Patrícia Loureiro Abreu Alves. Nome de domínio como sinal distintivo empresarial: análise das decisões dos Centros de Solução de Controvérsias credenciados 
pelo Comitê Gestor da Internet no Brasil. Tese (Doutorado em Direito) - Faculdade de Direito, Universidade Federal de Santa Catarina, Florianópolis, 2015

BARBOSA, Pedro Marcos Nunes. E-stabelecimento: Teoria de estabelecimento comercial na internet, aplicativos, websites, segregação patrimonial, trade dress eletrônico, concorrência online, ativos intangíveis cibernéticos e negócios jurídicos, São Paulo: Quartier Latin, 2018

BARBOSA, Rui. Obras completas de Rui Barbosa, v.II 1872-1874, tomo I. Rio de Janeiro: Fundação Casa de Rui Barbosa, 1984

BARROS, Alice Monteiro de. Curso do direito do trabalho. 10ed. São Paulo: LTR, 2016

BASSO. Maristela. O Direito Internacional da Propriedade Intelectual, Porto Alegre: Livraria do Advogado, 2000

BEVERLEY-SMITH, Huw; OHLY, Ansgar; LUCAS-SCHLOETTER, Agnès. Privacy, property and personality. Cambridge: Cambridge University Press, 2005

BEVILÁQUA, Clóvis. Código Civil dos Estados Unidos do Brasil Comentado, 7ed. v.I. Rio de Janeiro: Francisco Alves, 1944

. Código Civil dos Estados Unidos do Brasil Comentado. 10ed. atual. Por Achilles Beviláqua e Isaías Beviláqua, v.1. São Paulo: Francisco Alves, 1955

BITTAR, Carlos Alberto. Os direitos da personalidade. 7 ed. atual. por Eduardo Carlos Bianca Bittar. Rio de Janeiro: Forense Universitária, 2008.

BOBBIO, Norberto. A era dos direitos. 9ed. Tradução de Carlos Nelson Coutinho. Rio de Janeiro: Elsevier, 2004.

BRASIL. MINISTÉRIO PÚBLICO FEDERAL. CÂMARA DE COORDENAÇÃO E REVISÃO, 2. Roteiro de atuação: crimes cibernéticos. 2ed. rev. Brasília: MPF/2a CCR, 
2013. Disponível em < http://www.mpf.mp.br/atuacao-tematica/ccr2/publicacoes/roteiroatuacoes/docs-cartilhas/crimes_ciberneticos_web.pdf >, Acesso em 17 jan 2019

BUZAID, Alfredo. Do ônus da prova. In Revista da Faculdade de Direito da Universidade de São Paulo. São Paulo. v. 57, 1962. P. 113-140. Disponível em < http://www.revistas.usp.br/rfdusp/article/viewFile/66398/69008 > Acessado em 14 abr 2016

CANOTILHO, José Joaquim Gomes. Direito constitucional e teoria da constituição. 7. ed. Coimbra: Almedina, 2003.

CARBONNIER, Jean. Droit civil. 1 Introduction, les Personnes. 12ed. Paris: Presses Universitaries de France, 1979.

CARVALHO DE MENDONÇA, José Xavier. Tratado de direito comercial brasileiro. 3.ed. posta em dia por Achilles Bevilaqua e Roberto Carvalho de Mendonça, v.II Rio de Janeiro: Freitas Bastos, 1937

Tratado de direito comercial brasileiro. 3.ed. posta em dia por Achilles Bevilaqua e Roberto Carvalho de Mendonça, v.V Rio de Janeiro: Freitas Bastos, 1938

CASTRO, Carlos Roberto Siqueira. A constituição aberta e os direitos fundamentais: ensaios sobre o constitucionalismo pós-moderno e comunitário. Rio de Janeiro: Forense, 2005.

CERQUEIRA, João da Gama. Tratado da propriedade industrial. v.1. Introdução. Evolução histórica da propriedade industrial no Brasil. Rio de Janeiro: Forense, 1946

Tratado da propriedade industrial. v.2. Das marcas de fábrica e de comércio, do nome empresarial, das insígnias, das frases de propaganda, das recompensas industriais e da concorrência desleal. Rio de Janeiro: Forense, 1956

CHAVES, Antônio. Tratado de Direito Civil, v. 1. 3ed. São Paulo: Revista dos Tribunais, 1982. 
- Direito à vida e ao próprio corpo. (Intersexualidade, transexualidade e transplantes). 2ed. rev. e ampl. São Paulo: Revista dos Tribunais, 1994.

. Direito do autor: princípios fundamentais. Rio de Janeiro: Forense, 1987.

CHINELLATO, Silmara Juny de Abreu. Cf. Silmara Juny de Abreu Chinellato, Reprodução humana assistida: aspectos civis e bioéticos. Tese (Livre-Docência em Direito Civil) Faculdade de Direito, Universidade de São Paulo, São Paulo, 2000

. Direito de autor e direitos da personalidade: reflexões à luz do código civil. Tese (Concurso para Professor Titular) - Faculdade de Direito da Universidade de São Paulo, 2008.

Tutela civil do nascituro. São Paulo: Saraiva, 2000.

CIFUENTES, Santos. Derechos personalísimos. 2ed.actualizada y ampliada. Buenos Aires: Astrea, 1995

COELHO, Fabio Ulhoa, Curso de Direito Comercial, v. 1. 20ed. rev. atual. e ampl. São Paulo: revista dos Tribunais, 2016

COMPARATO, Fábio Konder. Etica: direito, moral e religião no mundo moderno. São Paulo: Companhia das Letras, 2006

COMYNS, Sir John; STEWART, Kyd. A digest of the laws of England. 4ed. vol. I Dublin: Luke White, 1793

COOLEY, Thomas McIntyre. A treatise on the law of torts or the wrongs which arise independent of contract. Chicago: Callaghan, 1879.

CORDEIRO, ANTÓNIO MENEZES. Tratado de Direito Civil, Tomo I. 4ed. ref. e atual. Coimbra: Almedina, 2017 
COSTA, Ligia Maura. A pirataria do nome de domínio na internet, RAE - Revista de Administração de Empresas, v. 41, n. 1, p. 45-53, São Paulo, disponível em < http://www.scielo.br/pdf/rae/v41n1/v41n1a06.pdf > Acesso em 17 jan 2019

COSTA NETTO, José Carlos. Direito autoral no Brasil. 2 ed. ver., ampl. e atual. São Paulo: FTD, 2008.

DE CUPIS, Adriano. Os direitos da personalidade. Tradução de Afonso Celso Furtado Rezende. 2ed. São Paulo: Quorum, 2008.

I diritti della personalità, 2 ed. Milão: Giuffrè, 1982.

DEL-CAMPO, Eduardo Roberto Alcântara, Medicina Legal I. 6ed. reformulada. São Paulo: Saraiva, 2009

DELGADO, Mauricio Godinho. Curso de direito do trabalho. 11 ed. São Paulo: LTR, 2012

DI FRANCO, Luigi. Trattato della proprietá industriale. Milão: Società Editrice Libraria, 1933.

DIAS, José de Aguiar. Da responsabilidade civil. 12 ed., rev., atual. de acordo com o Código Civil de 2002 e aumentada por Rui Bedford Dias. Rio de Janeiro: Lumen Juris, 2011.

DIAS, Maria Berenice. Divórcio: Emenda Constitucional 66/2010 e o CPC. 3ed. rev. atual. e ampl. São Paulo: Revista dos Tribunais, 2017 . Homoafetividade e os direitos LGBTI. 7ed. rev. atual. ampl. São Paulo: RT, 2017

DIAS, Rodrigo Bernardes. Privacidade genética. São Paulo: SRS, 2008

DINIZ, Maria Helena. Curso de direito civil brasileiro, v. 1 : teoria geral do direito civil. 29. ed. São Paulo: Saraiva, 2012. 
DONEDA, Danilo. Da Privacidade à proteção de dados pessoais. São Paulo: Renovar, 2006.

DUVAL, Hermano. Concorrência desleal. São Paulo: Saraiva, 1976

EUROPEAN PARLIAMENT. European civil law rules in robotics. Study for the JURI

Committee. Bruxelas: European Parliament, 2016. Disponível em < http://www.europarl.europa.eu/RegData/etudes/STUD/2016/571379/IPOL_STU\%282016 \%29571379_EN.pdf $>$ Acesso em 17 jan 2019

FERRARA, Francesco. Tratatto di diritto civile, t.1, Roma: Athenaeum, 1921

FERREIRA, Waldemar. Tratado de Direito Comercial, v.2. São Paulo: Saraiva, 1960

FRANÇA, Rubens Limongi. Do nome civil das pessoas naturais. 2ed. rev. São Paulo: Revista dos Tribunais, 1964.

. Instituições de direito civil. 5ed. rev. e atual. São Paulo: Saraiva, 1999.

. Manual de Direito Civil. v. 1. 2ed. São Paulo: Revista dos Tribunais, 1971.

. Direitos da personalidade - coordenadas fundamentais. Revista da Academia Brasileira de Letras Jurídicas, Rio de Janeiro, v. 7, n. 4, p. 37-50, 1993.

GOGLIANO, Daisy. Direitos privados da personalidade. São Paulo: Quartier Latin, 2012.

GOMES, Orlando. Introdução ao Direito Civil. 2ed. Rio de Janeiro: Forense, 1965.

Introdução ao Direito Civil. 18ed. Atualização e Notas por Humberto Theodoro Júnior. Rio de Janeiro: Forense, 2001.

HOMEYER, Carl Gustav. Die Haus-Und Hofmarken, Berlim: Verlag der Königlichen Geheimen Ober-Hofbuchdruckerei, 1870 
JELLINEK, Georg. La Declaración de los Derechos del Hombre y Ciudadano. Trad. A. Posada. Madrid: 1908

KELSEN, Hans. Teoria pura do direito. 5. ed. São Paulo: Revista dos Tribunais, 2007.

IHERING, Rudolf von. Struggle for law. 5ed. Trad. John L. Lalor. Chicago: Callaghan and Company, 1879.

Actio Iniuriarum - Des Lésions Injurieuses en Droit Romain et en droit francais.

Traduzido para o francês de Octave Meulenaere. Paris: Libraire Maresq, 1888

JESUS, Damásio de. Código Penal Anotado. 22ed. São Paulo: Saraiva, 2014

LADAS, Stephen Pericles. Patents, Trademarks, and Related Rights. National and International Protection, v.1, Cambridge: Harvard University Press: 1975

LEONARDI, Marcel. Tutela e Privacidade na Internet. São Paulo: Saraiva, 2012 . Code and other laws of cyberspace, version 2.0. Nova York: Basic Brooks, 2006.

LOPEZ, Teresa Ancona. Princípio da precaução e evolução da responsabilidade civil. São Paulo: Quartier Latin, 2010

MEIRELLES, Hely Lopes, WALD, Arnoldo e MENDES, Gilmar Ferreira. Mandado de segurança. 32ed. São Paulo: Malheiros, 2009

MORAES, Alexandre de. Direito Constitucional. 23ª ed. São Paulo: Atlas, 2008.

MORATO, Antonio Carlos. Pessoa jurídica consumidora. São Paulo: Revista dos Tribunais, 2008

MOREIRA ALVES, José Carlos. Direito romano. 15 ed. Rio de Janeiro, Forense, 2012. 
NEVES, Daniel Amorim Assumpção Manual de direito processual civil. Vol. único. 7ed. São Paulo: Método, 2015. Edição VitalBook

O’CALLAGHAN, Patrick. Refining privacy in Tort Law. Nova Iorque: Springer, 2013

ODGERS, Blake. A digest of the law of libel and slander with the evidence, procedure, practice, and precedents of pleadings both in civil and criminal cases. 3ed. Londres: Stevens and Sons Ltd, 1896

OLIVEIRA, José Lamartine Correia de. A dupla crise da pessoa jurídica. São Paulo: Saraiva, 1979

PALMER, Vernon Valentine. The Recovery of Non-Pecuniary Loss in European Contract Law. Cambridge: Cambridge University Press: 2015

PERLINGIERI, Pietro. La personalità umana nell'ordinamento giuridico. Camerino: Jovene, 1972

PINHEIRO, Patricia Peck. Direito digital. $6^{\text {a }}$ ed. rev. atual. e ampl. São Paulo: Saraiva, 2016.

PONTES DE MIRANDA, Francisco Cavalcanti. Tratado de direito privado. Parte geral. Tomo I. Introdução. Pessoas Físicas e Jurídicas. 1 ed em e-book. Atualizado por Judith Martins-Costa, Gustavo Haical e Jorge Cesar Ferreira da Silva. São Paulo: Revista dos Tribunais, 2015. Edição Thomson Reuters Proview

. Tratado de direito privado. Parte especial. Tomo VII. Direito de Personalidade. Direito de Família. 1 ed em e-book. Atualizado por Rosa Maria de Andrade Nery. São Paulo: Revista dos Tribunais, 2015. Edição Thomson Reuters Proview . Tratado de direito privado. Parte especial. Tomo XV. Direito das Coisas. Propriedade Mobiliária (Bens Corpóreos). 1 ed em e-book. Atualizado por Otavio Luiz Rodrigues Junior e Jefferson Carús Guedes. São Paulo: Revista dos Tribunais, 2015. Edição Thomson Reuters Proview 
. Tratado de direito privado. Parte especial. Tomo XVI. Direito das Coisas. Propriedade Mobiliária (Bens Incorpóreos). Propriedade intelectual. Propriedade industrial. 1 ed em e-book. Atualizado por Marcos Alberto Sant'Anna Bitelli. São Paulo: Revista dos Tribunais, 2015. Edição Thomson Reuters Proview

. Tratado de direito privado. Parte especial. Tomo XVII. Direito das Coisas. Propriedade Mobiliária (Bens Incorpóreos). Propriedade industrial (sinais distintivos). 1 ed em e-book. Atualizado por Carlos Henrique de Carvalho Fróes. São Paulo: Revista dos Tribunais, 2015. Edição Thomson Reuters Proview

. Tratado de direito privado. Parte especial. Tomo XXII. Direito das Obrigações. Obrigações e suas espécies. Fontes e espécies de obrigações. 1 ed em e-book. Atualizado por Nelson Nery Júnior e Rosa Maria de Andrade Nery. São Paulo: Revista dos Tribunais, 2015. Edição Thomson Reuters Proview

Tratado de direito privado. Parte especial. Tomo LII. Direito das Obrigações. Fatos ilícitos absolutos. Atos-fatos ilícitos absolutos. Atos ilícitos absolutos. Responsabilidade. Danos causados por animais. Coisas inanimadas e danos. Estado e servidores. Profissionais. Atualizado por Rui Stocco. São Paulo: Revista dos Tribunais, 2015. Edição Thomson Reuters Proview

POUILLET, Eugène. Traité de marques de fabrique et de la concurrence déloyale en tous genres. 6ed. Paris: Place Dauphine, 1912

REALE, Miguel. Fundamentos do Direito. 2 ed. rev. São Paulo: EDUSP, 1972, p. 302-307.

RIPERT, Georges. A regra moral nas obrigações civis. Tradução Osório de Oliveira. Campinas: Bookseller, 2002.

RODOTÁ, Stefano. A vida na sociedade da vigilância. A privacidade hoje. Trad. por Danilo Doneda e Luciana Cabral Doneda. Rio de Janeiro: Renovar, 2008

SAVIGNY, Friedrich Carl von. Sistema del derecho romano actual. Trad. por Jacinto Mesía e Manuel Poley. Madri: F. Góngora y Compañía, 1878, tomo 1 
. Sistema del derecho romano actual. Trad. por Jacinto Mesía e Manuel Poley. Madri:

F. Góngora y Compañía, 1879, tomo 2

SCALQUETTE, Ana Claudia Silva, Estatuto da reprodução assistida. Tese (Doutorado em

Direito Civil) - Faculdade de Direito, Universidade de São Paulo, São Paulo, 2009. doi:10.11606/T.2.2009.tde-08032010-095921. Acesso em 17 jan 2019

SCHMIDT, Lélio Denicoli. A distintividade das marcas. Secondary meaning, vulgarização e teoria da distância. São Paulo: Saraiva, 2013

SCHREIBER, Anderson. Direitos da personalidade. 3ed. rev. e atual. São Paulo: Atlas, 2014.

. Novos paradigmas da responsabilidade civil: da erosão dos filtros da reparação à diluição dos danos. 6ed. São Paulo: Atlas, 2015

SERPA LOPES, Miguel Maria de. Tratado dos registos públicos. vol. 1. Parte Geral: Registos Públicos - Registo Civil das Pessoas Naturais - Registo Civil das Pessoas Jurídicas - Registo de Imóveis - Registo da Propriedade Literária, Científica e Artística. Parte Especial: Registo Civil de Nascimento - Registo de Casamento - Registo de Óbito - Filiação - Emancipação - Retificação. Rio de Janeiro: Freitas de Bastos, 1960

. Curso de Direito Civil. v. 1 8ed. rev. e atual. por José Serpa Santa Maria. Rio de Janeiro: Freitas Bastos, 1996.

SESSAREGO, Carlos Fernández. Derecho a la identidad personal. Buenos Aires: Astrea, 1992.

SILVA, José Afonso da. Curso de direito constitucional positivo. 37 ed. São Paulo: Malheiros, 2014.

SILVEIRA, Newton. Propriedade intelectual. Propriedade industrial, direito de autor, software, cultivares, nome empresarial e abuso de patentes. 5ed. revisada e ampliada. Barueri: Manole, 2014 
SOARES, José Carlos Tinoco. Tratado da propriedade industrial. Marcas e congêneres. v.1, São Paulo: Jurídica Brasileira, 2003

SOLOVE, Daniel J. Understanding privacy. Cambridge: Harvard University Press, 2009.

SOUSA, Rabindranath Valentino Aleixo Capelo de. $O$ direito geral de personalidade. Coimbra: Coimbra, 2011.

SOUZA, Daniel Adensohn de. A proteção jurídica do nome de empresa no Brasil. 2009. Dissertação (Mestrado em Direito Comercial) - Faculdade de Direito, Universidade de São Paulo, São Paulo, 2009. doi:10.11606/D.2.2009.tde-16042010-123306.

SZANIAWSKI, Elimar. Direitos de personalidade e sua tutela. 2 ed. rev., atual., e ampl. São Paulo: Revista dos Tribunais, 2005.

THEODORO JÚNIOR, Humberto. Curso de direito processual civil. V. I, 58ed. Rio de Janeiro: Forense, 2017. Edição VitalBook.

THOMAS, Starkie. A treatise on the law of slander, libel, scandalum magnatum, and false rumours: including the rules which regulate intellectual communications, affecting the characters of individuals and the interests of the public: with a description of the practice and pleadings of personal actions, informations, indictments, attachments for contempts, $\& c .$, connected with the subject. Nova Iorque: G. Lamson, 1826

TOBEÑAS. José Catstán, in Los derechos de la personalidad. Madrid: Reus, 1952

VALE E REIS, Rafael Luís. O direito ao conhecimento das origens genéticas. Coimbra: Coimbra, 2008

VENOSA, Silvio de Salvo. Direito Civil. v. II. Teoria Geral das Obrigações e Teoria Geral dos Contratos. 5ed. São Paulo: Atlas, 2005 


\section{CAPÍTULOS DE LIVROS}

BARROSO, Luiz Roberto. Legitimidade da recusa de transfusão de sangue por testemunhas de Jeová. Dignidade humana, liberdade religiosa e escolhas existenciais. In: Direitos do paciente. Coordenação Álvaro Villaça Azevedo e Wilson Ricardo Ligiera. São Paulo: Saraiva, 2012

BENTLY, Lionel. Identity and the Law, in Identity, Giselle Walker e Elisabeth LeedhamGreen (ed.). Londres: Cambridge University Press, 2010, p. 26-58.

CHINELLATO, Silmara Juny. Arts. 1 a 21. In: CHINELLATO, Silmara Juny (org.). Código Civil Interpretado. Artigo por artigo, parágrafo por parágrafo. Barueri: Manole, 2017,

CHINELLATO, Silmara Juny de Abreu. O nome da mulher no casamento, separação, divórcio, união estável e viuvez: nova visão à luz dos direitos da personalidade. In Josefina Maria de Santana (coord.) A Mulher e o Direito. São Paulo: Lex, 2007

DE CUPIS, Adriano. Sezione I civile; sentenza 7 dicembre 1960, n. 3199; Pres. Lorizio P., Est. Favara, P. M. Silocchi (concl. conf.); Soc. Adriatica Film (Avv. Salvadori del Prato) c. Bernuzzi (Avv. Corsi, Garampelli) e Soc. Manzotin. Il Foro Italiano, vol. 84. Roma: 1961, p. $43-48$

DI MATTIA, Fabio Maria. Direitos de personalidade - II. in FRANÇA, Rubens Limongi (org.). Enciclopédia Saraiva do Direito, v. 28, p. 156. São Paulo: Saraiva, 1977.

FROSINI, Vittorio. Diritto alla riservatezza e calcolatori elettronici. In ALPA, Guido; BESSONE, Mario (org.) Banche dati telematica e diritti della persona. Padova: Cedam, 1984 , p. 37.

FLORINO, L. Sezione I civile; sentenza 13 luglio 1971, n. 2242; Pres. Mirabelli, Est. Brancaccio, P. M. Minetti (concl. conf.); Noya di Lannoy (Avv. Moschella, C. A. Funaioli) c. Pres. Cons. ministri (Avv. dello Stato Fanelli), Sovrano militare ordine di Malta (Avv. Gazzoni). Il Foro Italiano, vol. 95. Roma: 1972, 433-444. 
MORAES, Walter. Direito à própria imagem. in FRANÇA, Rubens Limongi (org.). Enciclopédia Saraiva do Direito, v. 25, p. 340-362. São Paulo: Saraiva, 1977.

PIZZORUSSO, A. “Ordinanza 30 Maggio 1979; Giud. Burbatti; Pannella c. Gianotti.” Il Foro Italiano, vol. 103. Roma: 1980, p. 2079-2084.

PARDOLESI, R. "Sezione I civile; sentenza 22 giugno 1985, n. 3769; Pres. Falcone, Est. Tilocca, P. M. La Valva (concl. conf.); Soc. Austria Tabakwerke GmbH (Avv. Dente) c. Veronesi (Avv. Carbone, Faggioni) e Istituto nazionale per lo studio e la cura dei tumori (Avv. Dondina). Conferma App. Milano 2 novembre 1982." Il Foro Italiano, vol. 108. Roma: 1985, p. 2211-2218.

PODESTA, Fabio Henrique, Marco civil da internet e direitos da personalidade in DE LUCCA, Newton; SIMÃO FILHO, Adalberto; LIMA, Cíntia Rosa Pereira de (coords.). Direito \& Internet III - Tomo I: Marco Civil da Internet (Lei n $\left.{ }^{\circ} 12.965 / 2014\right)$ - São Paulo: Quartier Latin, 2015

SEIDL, Horst. The concept of person in St. Thomas Aquinas: a contribution to recent discussion. The Thomist: A Speculative Quarterly Review, v. 51, n. 3, julho 1987, pp. 435460, Doi: 10.1353/tho.1987.0016

SOCIETA EDITRICE IL FORO ITALIANO ARL. Sentenza 22 maggio 1964; Pres. Trimarchi P., Est. Donati; Soc. Zebra film (Avv. Vigevani, Graziadei) c. Bertoni (Avv. Formiggini Pasotelli); Bertoni (Avv. Formiggini Pasotelli) c. Soc. Rizzoli editore e Cineriz noleggio film (Avv. Majno, Ceva), Montanelli (Avv. Paggi, Zaso, Zamboni), Amidei, Fabbri, Zuffi, Rossellini (n. c.); Soc. Rizzoli editore e Cineriz noleggio film c. Bertoni; Bertoni c. Soc. Zebra film. (1964). Il Foro Italiano Vol. 87, Parte Prima: Giurisprudenza Costituzionale e Civile. Roma, 1964, p. 1239-1246.

. Il Foro Italiano Vol. 97, Parte Prima: Giurisprudenza Costituzionale e Civile. Roma, 1974, p. 1806-1810. 


\section{ARTIGOS E AULAS}

BITTAR, Carlos Alberto. O poder legislativo e o Direito de Autor. Revista de Informação Legislativa do Senado Federal. a. 26, n. 101, jan./mar. 1989, p. 135-146

BODIN DE MORAES, Maria Celina; DE CASTRO, Thamis Dalsenter Viveiros. A autonomia existencial nos atos de disposição do próprio corpo. Pensar. v. 19, n. 3, p. 779818, set./dez. 2014. doi: http://dx.doi.org/10.5020/23172150.2012.779-818 Acesso em 17 jan 2019

CHAVES, Antônio. Direitos da personalidade e dano moral. Revista Jurídica: órgão nacional de doutrina, jurisprudência, legislação e crítica judiciária. Ano XLIV, n. 220, fevereiro de 1996. Porto Alegre: Síntese, 1996.

. Direitos à vida, ao próprio corpo e às partes do mesmo (transplantes). Esterilização e operações cirúrgicas para "mudança de sexo". Direito ao cadáver e às partes do mesmo. Revista da Faculdade de Direito da Universidade de São Paulo. 72(1), 243-298. Disponível em < http://www.revistas.usp.br/rfdusp/article/view/66797/69407 >, Acesso em 17 jan 2019

COYNE, Randall T.E. Toward a Modified Fair Use Defense in Right of Publicity Cases, Wm. \& Mary L. Rev., v.29 n. 4, Williamsburg, Estados Unidos da América, 1988. http://scholarship.law.wm.edu/wmlr/vol29/iss4/4

DAINOW, Joseph. The Civil Law and the Common Law: some points of comparison. The American Journal of Comparative Law, v. 15, n. 3 (1966 - 1967), p. 419-435. Disponível em < http://www.jstor.org/stable/838275 > Acesso em 17 jan 2019

DIAS. Maria Berenice. Em nome do que Disponível em < http://www.mariaberenice.com.br/manager/arq/(cod2_727)15_em_nome_do_que.pdf > Acesso em 17 jan 2019

DWORKIN, Gerald. The Common Law protection of privacy. University of Tasmania Law Review. $\quad$ v. 2, n. 4 (1967), p. 418-445 Disponível em < http://www.austlii.edu.au/au/journals/UTasLawRw/1967/4.html 
FERNÁNDEZ BURGUEÑO, Pablo (2012). Aspectos jurídicos de la identidad digital y la reputación online. En: adComunica. Revista Científica de Estrategias, Tendencias e Innovación en Comunicación, $\mathrm{n}^{\circ} 3$. Castellón: Asociación para el Desarrollo de la Comunicación adComunica, Universidad Complutense de Madrid y Universitat Jaume I, 125-142. DOI: http://dx.doi.org/10.6035/2174-0992.2012.3.8, Acesso em 17 jan 2019

FINOCCHIARO, Giusella Dollores. Identità personale (diritto alla). DIGESTO delle discipline privatistiche. Sezione civile. Aggiornamento. v. 6. Turim: Utet Giuridica, 2011, p. $721-737$.

HAIKAL, Victor Auilo. Da necessidade de inclusão de URL em ordens judiciais. Revista dos Tribunais (São Paulo. Impresso), v. 944, p. 411-439, 2014

INTERNATIONAL TELECOMMUNICATION UNION. Declaration of principles building the information society: a global challenge in the new millennium. Disponível em < https://www.itu.int/net/wsis/docs/geneva/official/dop.html > Acesso em 17 jan 2019

- Tunis commitment. Disponível em https://www.itu.int/net/wsis/docs2/tunis/off/7.html > Acesso em 17 jan 2019

MORATO, Antonio Carlos. Proteção aos direitos da personalidade em meio eletrônico. Pós-graduação da Faculdade de Direito da Universidade de São Paulo (USP), São Paulo. Disponível em:

http://disciplinas.stoa.usp.br/pluginfile.php/130630/mod_resource/content/1/USP\%20$\% 20$ Prote $\%$ C3\%A7\%C3\%A3o\%20aos\%20Direitos\%20da\%20Personalidade\%20em\%20 meio\%20eletr\%C3\%B4nico\%20-\%20Biografias\%20n\%C3\%A3o\%20autorizadas.pdf > Acesso em 17 jan 2019

Quadro geral dos direitos de personalidade. Revista da Faculdade de Direito da Universidade de São Paulo. v. 106/107. p. 121-158. DOI: http://dx.doi.org/10.11606/issn.2318-8235.v106i106-107p121-158 Acesso em 17 jan 2019 
PROSSER, William Lloyd. Privacy. California Law Review. v. 48. p. 383-423. Ago 1960. DOI: https://doi.org/10.15779/Z383J3C. Acesso em 17 jan 2019

RAFFIOTTA, Edoardo Carlo. Appunti in materia di diritto all'identità personale. In Forum di Quaderni Costituzionali. 26 Jan 2010. Disponível em < http://www.forumcostituzionale.it/wordpress/images/stories/pdf/documenti_forum/paper/0

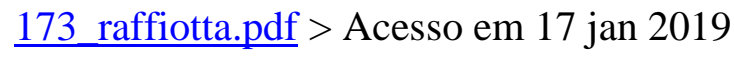

ROSLER, Hannes. Dignitarian posthumous personality rights - an analysis of U.S. and German constitutional and tort law. Berkeley J. Int'l Law. v. 26, p. 153-205, 2008. Disponível em https://scholarship.law.berkeley.edu/cgi/viewcontent.cgi?article=1351\&context=bjil > Acesso em 17 jan 2019

SOLUM, Lawrence B. Legal Personhood for Artifcial Intelligences, North Carolina Law Review, v. 70, n. 4, abr 1992. Disponível em < http://scholarship.law.unc.edu/nclr/vol70/iss4/4 > Acesso em 17 jan 2019

SULliVAN, Clare; STALLA-BOURDILlON, Sophie. Digital identity and French personality rights - A way forward in recognizing and protecting an individual's rights in his/her digital identity. Computer Law \& Security Review, v. 31, n. 2, Abril 2015, p. 268279, doi: https://doi.org/10.1016/j.clsr.2015.01.002, Acesso em 17 jan 2019

TEIXEIRA, Tarcísio. Nome empresarial. Revista da Faculdade de Direito da Universidade de São Paulo, v. 108, p. 271-299, 22 nov. 2013. Disponível em < http://www.revistas.usp.br/rfdusp/article/view/67986/pdf_11 > Acesso em 17 jan 2019

UNIÃO EUROPEIA. Report with recommendations to the Commission on Civil Law Rules on Robotics (2015/2103(INL)), 27 Jan 2017. Disponível em < http://www.europarl.europa.eu/sides/getDoc.do?pubRef=-//EP//TEXT+REPORT+A82017-0005+0+DOC+XML+V0//EN > Acesso em 17 jan 2019

VIEIRA, Tereza Rodrigues. Nome e sexo. Mudanças no Registro Civil. 2ed. São Paulo: Atlas, 2012 
WARREN, Samuel Dennis; BRANDEIS, Louis Dembitz. The right of privacy, in Harvard Law Review, 193, 1890. Disponível em < http://links.jstor.org/sici?sici=0017811X\%2818901215\%294\%3A5\%3C193\%3ATRTP\%3E2.0.CO\%3B2-C > Acesso em 17 jan 2019

\subsection{OBRAS GERAIS E DE OUTRAS ÁREAS DO CONHECIMENTO}

\section{LIVROS}

(ISC) $)^{2}$. Official (ISC) ${ }^{2 \circledR}$ Guide to the CISSP ${ }^{\circledR} C B K^{\circledR}$. 4ed. Boca Raton: CRC Press, 2015, Edição Kindle

ABREU, Sara Matos. BDSM: No Limiar do Consentimento Sexual. Dissertação (Mestrado em Psicologia da Justiça: Vítimas de Violência e Crime) - Faculdade de Ciências Humanas e Sociais da Universidade Fernando Pessoa, Porto, 2017. Disponível em < https://bdigital.ufp.pt/bitstream/10284/6026/1/DM_Sara\%20Matos\%20Abreu.pdf > Acesso em 17 jan 2019

ALI, Imam Ibn Abi Talib. Peak of eloquence. Provérbios. In: BÍBLIA. Português. Bíblia sagrada. Antigo Testamento. Tradução de João Ferreira de Almeida. 2 ed. Rio de Janeiro: Sociedade Bíblica do Brasil. p. 1210.

ALLPORT, Gordon Willard. Personality. A psychological interpretation. Londres: Constable \& Company, 1956.

Pattern and growth in personality. Nova Iorque: Holt, Rinehart and Winston, 1961.

ANDERSON, Chris. The long tail. how endless choice is creating unlimited demand. Londres: Random House Business Books, 2009

BAASE, Sara. A gift of fire.4 ed. New Jersey: Pearson, 2013. 
BACON, Francis. In Religious meditations. Londres: Iohn Iaggard, 1613. Disponível em < https://archive.org/stream/essaiesofsrfranc00baco\#page/180/mode/2up > Acesso em 17 jan 2019

BAUMAN, Zygmunt. Identity. Conversations with Benedetto Vecchi. Cambridge: Polity Press, 2004. Edição do Kindle Liquid Modernity. Cambridge: Polity Press, 2012.

BAYLE, Pierre. A general dictionary. Historical and Critical. v. VIII. Londres: J. Bettenham, 1739

BERNERS-LEE, Tim. Weaving the web: the original design and ultimate destiny of the World Wide Web by its inventor. Nova York: HarperCollins Publishers, 2000

BÍBLIA. A. T. Provérbios. In: BÍBLIA. Português. Bíblia sagrada. Antigo Testamento. Tradução de João Ferreira de Almeida. 2 ed. Rio de Janeiro: Sociedade Bíblica do Brasil. p. 1210 .

BLUM, Bruce I. Beyond Programming. To a new era of design. Nova Iorque: Oxford University Press, 1996.

BURTON, Arthur. Teorias operacionais da personalidade. Trad. por Carlos Alberto Pavanelli. Rio de Janeiro: Imago, 1978.

CAMPBELL-KELLY, Martin. Computing. Scientific American, 2009. Disponível em < http://www.cs.virginia.edu/ robins/The_Origins_of_Computing.pdf $>$ Acesso em 17 jan 2019

CASTELLS, Manuel. The information age: economy, society and culture. The rise of the network society. 2 ed. Oxford: Blackwell Publishing, 2010. Edição Kindle

The power of identity: the information age: economy, society, and culture Volume II. 2 ed. Oxford: Blackwell Publishing, 2010. Edição Kindle 
. The politics of the internet II: privacy and liberty in cyberspace, in the internet galaxy: reflections on the Internet, business and society. Oxford: Oxford University Press, 2002.

. Communication power. 2 ed. Oxford: Oxford University Press, 2013. Edição do Kindle.

CLYMER, A. Ben. The mechanical analog computers of Hannibal Ford and William Newell. IEEE Annals of the History of Computing v. 15:2, 1993

CRAWFORD, Susan. The origin and development of a concept: The Information Society. Bull. Med. Libr. Assoc. 71(4) Outubro 1983. Disponível em < https://www.ncbi.nlm.nih.gov/pmc/articles/PMC227258/pdf/mlab00068-0030.pdf > Acesso em 17 jan 2019

COMITÊ GESTOR DA INTERNET. Documentos da Cúpula Mundial sobre a Sociedade da Informação. Genebra 2003 e Túnis 2005. São Paulo: Comitê Gestor da Internet, 2014.

CULKIN, John. A schoolman's guide to Marshall Mcluhan. The Saturday Review. 18 de Março de 1967

DAVIES, Susanna in Introduction: information, knowledge and power. IDS Bulletin 25.2, 1994. Disponível em < https://www.ids.ac.uk/files/dmfile/davies252.pdf >

DENNING, Peter J.; et al. "Computing as a Discipline". Communications of the $\underline{\text { ACM. }}$. Association for Computing Machinery. 32: 9-23. doi: $10.1145 / 63238.63239$

DESCARTES, René. Discours de La Méthode. Mozambook, 2001.

DRUKER, Peter. Age of Discontinuity. Guidelines to our changing society. Londres: Heinemann, 1969.

DUBAR, Claude. A socialização: construção das identidades sociais e profissionais. Trad. por Andréa Stahel M. da Silva. São Paulo, Martins Fontes, 2005 
DURKHEIM, Émile. Educação e Sociologia. Trad. por Prof. Lourenço Filho. 6ed. São Paulo: Melhoramentos, 1965

ERIKSON, Erik Homburger. Identity: youth and crisis. Nova Iorque: 1968, W. W. Norton \& Company

FERREIRA, Ermelinda. Fernando Pessoa e o Distúrbio de Personalidade Múltiplas. In: Intersemiose - Revista Digital, n. 1, 2012.

FREUD, Sigmund. The Ego and The Id. Complete works, trad. por James Strachey e editado por Ivan Smith, 2010, p. 3944-3992

GOODRICH, Michael; TAMASSIA, Robert. Introduction to Computer Security. Boston: Pearson Education, 2011.

GUNKEL. David J. Robot rights. Cambridge: MIT Press, 2018. Versão Kindle

HARRIS, W. V. Roman terracota lamps: The organization of an industry. The journal of Roman Studies, v.70, p. 126-145, 1980. Disponível em < http://www.jstor.org/stable/299559 > Acesso em 17 jan 2019

HOBBES, Thomas. Concerning body. 1655. In The English Works of Thomas Hobbes of Malmesbury. Now first collected and edited by Sir. Bart William Molesworth. v. 1. Londres: John Bohn, 1839

$$
\text { Leviathan. } \quad \text { Londres: 1651, Disponível em < }
$$
https://socialsciences.mcmaster.ca/econ/ugcm/3113/hobbes/Leviathan.pdf $>$ Acesso em 17 jan 2019.

HOBSBAWN, Eric J. A Era das Revoluções. 37ed. São Paulo: Paz e Terra, 2016

HUXLEY, Aldous. Brave New World. Londres: Vintage Books, 2007 
INTERNATIONAL ORGANIZATION FOR STANDARDIZATION. ISO/IEC 247601:2011 Information technology -- Security techniques -- A framework for identity management -- Part 1: Terminology and concepts. Suíça: International Organization for Standardization, 2011

JENSEN, Bill; KLEIN, Josh. Hacking work: breaking stupid rules for smart results. Nova Iorque: Penguin Group, 2010

JUNG, Carl Gustav. The archetypes and the collective unconscious. 2ed. Collected works of C.G. Jung. V.9.1. Trad. Por R. F. C. Hull. Princeton: Princeton University Press: 1969 Development of personality. 3ed. Collected works of C.G. Jung. V.17. Trad. Por R. F. C. Hull. Princeton: Princeton University Press: 1981

Practice of psychotherapy. 2ed. Collected works of C.G. Jung. V.16. Trad. Por R. F. C. Hull. Princeton: Princeton University Press: 1985

KAUFFMAN, Jean-Claude. A invenção de si: Uma teoria de identidade. Trad. Joana Chaves. Lisboa: Instituto Piaget, 2005

KADT, Emanuel de. Making health policy management intersectoral: Issues of information analysis and use in less developed countries. Social Science \& Medicine. v. 29 n. 4, 1989, p. 503-514

KURBALIJA, Jovan. Uma introdução à Governança da Internet. São Paulo: Comitê Gestor da Internet no Brasil, 2016. Trad. por Carolina Carvalho Disponível em < https://cgi.br/media/docs/publicacoes/1/CadernoCGIbr_Uma_Introducao_a_Governanca_d a_Internet.pdf > Acesso em 17 jan 2019

LEVY, Steven. Hackers. Heroes of the computer revolution. Nova Iorque: Dell Publishing, 1984

LOCARD, Edmond. Manuel de Technique Policière. Paris: Payot, 1923 
LOCKE, John. An essay concerning human understanding, Livro II. The Works of John Locke in Nine Volumes, v.1. 12ed. Londres: Rivington, 1824

LUTHER, Martin. Biometrics, VACCA, John R. (org.) Computer and information security handbook. Burlington: 2009

MAYER-SCHÖNBERGER, Viktor; CUKIER, Kenneth. Big data. Nova Iorque: First Mariner, 2014.

MCLUHAN, Stephanie; STAINES, David. (Org.). Understanding Me. Lectures and interviews by Marshall Mcluhan. Toronto: McClelland \& Stewart Ltd, 2004

MICHALUP, Franz. The production and distribution of knowledge in the United States, Princeton: Princeton University Press, 1962

MILL, John Stuart. On liberty, Londres: 1901. Versão em ebook Project Gutemberg. Disponível em http://www.gutenberg.org/ebooks/34901.epub.images?session_id=3cac69e8aa1f7ae739ec3 $\underline{180 \mathrm{e} 2 \mathrm{e} 05 \mathrm{f} 95 \mathrm{fe} 9 \mathrm{ccb} 9 \mathrm{~b}}>$ Acesso em 17 jan 2019

MONTESQUIEU, Barão de. The Spirit of Laws. The Complete Works of M. de Montesquieu. Londres: T. Evans, 1777

MURDOCK, George Peter, Our primitive contemporaries. Nova Iorque: Macmillan Company: 1934

NICKOLLS, L. C., The scientific investigation of crime. Londres: Butterworth \& Co., 1956

O’REILly, Tim. What Is Web 2.0: Design Patterns and Business Models for the Next Generation of Software. Communications \& Strategies, n. 65, 2007, p. 17. < http://mpra.ub.uni-muenchen.de/4580/1/ > Acesso em 17 jan 2019

OECD. OECD guide to measuring the information society. OECD, 2011. Disponível em http://dx.doi.org/10.1787/9789264113541-en Acesso em 17 jan 2019 
PESSOA, Fernando. Escritos Íntimos, Cartas e Páginas Autobiográficas. Introdução, organização e notas de António Quadros. Lisboa: Europa-América, 1986

RAYMOND, Eric S., The New Hacker's Dictionary. 3. ed. Disponível em < https://mitpress.mit.edu/books/new-hackers-dictionary > Acesso em 17 jan 2019

ROUSSEAU, Jean-Jaques. A discourse of inequality. Nova Iorque: Philosophical Library, 2016 . The Social Contract. Trad. Por G. D. H. Cole. 1762.

SARTRE, Jean-Paul. Being and Nothingness: An Essay on Phenomenological Ontology. Trad. de Hazel. E. Barnes. Nova Iorque: Philosophical Library, 1956

Existentialism and Human Emotions. Nova Iorque: Citadel, 1957

TAGG, Caroline. Discourse of Text Messaging: Analysis of SMS Communication. Nova Iorque: Continuum International, 2012

TAPSCOTT, Don. Grown up digital. How the net generation is changing your world. Nova Iorque: McGraw-Hill, 2009.

TAPSCOTT, Don; WILLIAMS, Anthony D. Macrowikinomics: Rebooting business and the world. London: Portfolio Penguin, 2010.

. Wikinomics. How mass collaboration changes everything. Londres: Atlantic Books, 2008.

TOFFLER, Alvin. Future shock. Nova Iorque: Bantam Books, 1970 The third wave. Nova Iorque: Bantam Books, 1980

VALACICH, Joe; SCHNEIDER, Cristoph. Information Systems Today: Managing the Digital World. Nova Jersey: Pearson, 2012 
WEBSTER, Frank. Theories of the information society. Nova Iorque: Routledge, 2006

World Intellectual Property Organization. The management of internet names and addresses: intellectual property issues. Final Report of the WIPO Internet Domain Name $\begin{array}{llllll}\text { Process. } & 30 & \text { abr } & 1999 . & \text { Disponível }\end{array}$ https://www.wipo.int/export/sites/www/amc/en/docs/report-final1.pdf > Acesso em 17 jan 2019

\section{CAPÍTULOS DE LIVROS}

BOSWORTH, Seymour; JACOBSON, Robert V. Brief history and missions of information system security. In BOSWORTH, Seymour; et. al. Computer Security Handbook. v. 1. 5 ed. Hoboken: John Wiley \& Sons, 2009

DITTRICH, David e HIMMA, Kenneth Elinar. Hackers, crackers and computer criminals, in BIGDOLI, Hossein. Handbook of information security. v. 1. Hoboken: John Wiley \& Sons, 2011.p. 137-154

INTERNATIONAL LABOR ORGANIZATION. The future of work and quality in the Information Society: The media, culture, graphical sector. Genebra: International Labor Organization, 2004. Disponível em < http://www.ilo.org/wcmsp5/groups/public/--ed_dialogue/---sector/documents/publication/wcms_161548.pdf >.

\section{ARTIGOS}

DYCK, Corey W. A Wolff in Kant's Clothing: Christian Wolff's Influence on Kant's Accounts of Consciousness, Self-Consciousness, and Psychology, Philosophy Compass, 6 : 44-53. doi:10.1111/j.1747-9991.2010.00370.x, Acesso em 17 jan 2019

ERDEN, Y. J. ICT Implants, Nanotechnology, and Some Reasons for Caution. Disponível em < https://www.bioethics.ac.uk/news/ICT-Implants-nanotechnology-and-some-reasonsfor-caution.php $>$ Acesso em 17 jan 2019

GALTON, Francis; WELDON, W. F. R.; PEARSON, Karl; DAVENPORT, C. B. Editorial. Biometrika, A journal for the statistical study of biological problems v.1, n.1, p. 1-6. Londres: Cambridge University Press, 1901. Disponível em: < 
https://ia800503.us.archive.org/12/items/biometrika119011902pear/biometrika119011902p

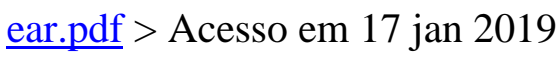

GALTON, Francis. Biometry. Biometrika, A journal for the statistical study of biological problems v.1, n.1, p. 7-10. Londres: Cambridge University Press, 1901. Disponível em: < https://ia800503.us.archive.org/12/items/biometrika119011902pear/biometrika119011902p ear.pdf $>$ Acesso em 17 jan 2019

HANSON, David; OLNEY, Andrew; PEREIRA, Ismar A.; ZIELKE, Marge. Upending the Uncanny. AAAI'05 Proceedings of the 20th national conference on Artificial intelligence v. 4 Valley. 9 jul 2005, p. 1728-1729. Disponível em < https://umdrive.memphis.edu/aolney/public/publications/Upending\%20the\%20uncanny\%2 0valley.pdf $>$ Acesso em 17 jan 2019

LIMA, Rita Lourdes de. Diversidade, identidade de gênero e religião: algumas reflexões, Revista da Faculdade de Serviço Social da Universidade do Estado do Rio de Janeiro. v.9, n.28, p. 165-182. Dez 2011. Disponível em < $\underline{\text { https://www.e- }}$ publicacoes.uerj.br/index.php/revistaempauta/article/download/2940/2104 > Acesso em 17 jan 2019

MACDONELL, W. R. On criminal antropometry ad the identification of criminals. Biometrika, A journal for the statistical study of biological problems v.1, n.1, p. 177-227. Londres: Cambridge University Press, 1901. Disponível em: < https://ia800503.us.archive.org/12/items/biometrika119011902pear/biometrika119011902p ear.pdf $>$ Acesso em 17 jan 2019

MASSACHUSSETS INSTITUTE OF TECHNOLOGY. The Tech. v. 83 n. 24 de 20 nov 1963. Disponível em < http://tech.mit.edu/V83/PDF/V83-N24.pdf >

PAUL, Christopher; MATTHEWS, Miriam. The Russian "Firehose of Falsehood" Propaganda Model. 2016. doi: 10.7249/PE198, Acesso em 17 jan 2019

PEARSON, Karl. On the fundamental conceptions of biology. Biometrika, A journal for the statistical study of biological problems v.1, n.1, p. 320-342. Londres: Cambridge University 
Press, 1901. Disponível em: < https://ia800503.us.archive.org/12/items/biometrika119011902pear/biometrika119011902p ear.pdf $>$ Acesso em 17 jan 2019

SALGADO, Richard P. Fourth amendment search and the power of the hash. Harvard. Law Review. $\quad$ v. 119, n. 38, p. 38-46 (2005) Disponível em < https://heinonline.org/HOL/P?h=hein.journals/forharoc119\&i=45 > Acesso em 17 jan 2019 Ali K. Yetisen. Biohacking. Science \& Society.| v. 36, n. 8, p. 744-747, 1 ago 2018. doi: https://doi.org/10.1016/j.tibtech.2018.02.011 Acesso em 17 jan 2019

DICIONÁRIOS ELETRÔNICOS E OUTROS CONTEÚDOS

STANFORD ENCYCLOPEDIA OF PHILOSOPHY. The modern history of computing. Disponível em < https://plato.stanford.edu/entries/computing-history/ > Acesso em 17 jan 2019

WIKIPEDIA: $\quad$ size comparisons. Disponível em https://en.wikipedia.org/wiki/Wikipedia:Size_comparisons > Acesso em 17 jan 2019

REPORTAGENS JORNALÍSTICAS OU PÁGINAS INSTITUCIONAIS

B'NAI B'IRTH. About Us, Disponível em < https://www.bnaibrith.org/about-us.html >, Acesso em 17 jan 2019

BOOTH, Robert. Facebook reveals news feed experiment to control emotions. The Guardian. $\quad 30$ jun 2014. Disponível em https://www.theguardian.com/technology/2014/jun/29/facebook-users-emotions-news-

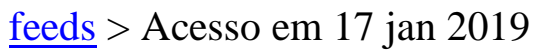

BRODWIN, Erin. I spent 2 weeks texting a bot about my anxiety - and found it to be surprisingly helpful. 20 jan 2018. Disponível em < https://www.businessinsider.com/therapy-chatbot-depression-app-what-its-like-woebot$\underline{2018-1}>$ Acesso em 17 jan 2019 
Here's the personality test Cambridge Analytica had Facebook users take. 19 mar

2018. Disponível em < https://www.businessinsider.com/facebook-personality-testcambridge-analytica-data-trump-election-2018-3 Acesso em 17 jan 2019

CAPANEMA, Rafael. Aplicativo que avalia homens vira febre entre as mulheres. $1 \mathrm{dez}$ 2013 < https://www1.folha.uol.com.br/cotidiano/2013/12/1379168-aplicativo-que-avaliahomens-vira-febre-entre-as-mulheres.shtml > Acesso em 17 jan 2019.

CNN.com. Couple try to name baby bin Laden. 5 set 2002. Disponível em < http://edition.cnn.com/2002/WORLD/europe/09/05/germany.osama/index.html >, Acesso em 17 jan 2019

EUGÊNIO JR., Amauri. O que é firehosing e como o clã Bolsonaro se aproveita disso. 11 out 2018. Disponível em < https://www.vice.com/pt_br/article/zm98ky/o-que-e-firehosinge-como-o-cla-bolsonaro-se-aproveita-disso $>$ Acesso em 17 jan 2019.

FACEBOOK INC. Que ferramentas o Facebook oferece para me ajudar a proteger minha propriedade intelectual nos meus vídeos? Disponível em < https://www.facebook.com/help/348831205149904 > Acesso em 17 jan 2019

FAUSTO, Sibele. Como está a Ciência no Mundo? Nov. 2015. Disponível em: < http://www.sibi.usp.br/noticias/acesso-aberto-mundo-2013-2015 >. Acesso em 17 jan 2019

FRANCE PRESSE. Em experimento secreto, Facebook manipula emoções de usuários. G1. 29 jun 2014. Disponível em < http://g1.globo.com/tecnologia/noticia/2014/06/emexperimento-secreto-facebook-manipula-emocoes-de-usuarios.html $>$ Acesso em 17 jan 2019

G1. Facebook impede que usuários mudem nome para 'Guarani-Kaiowá'. 11 jan 2013. Disponível em < http://g1.globo.com/tecnologia/noticia/2013/01/facebook-impede-queusuarios-mudem-nome-para-guarani-kaiowa.html > Acesso em 17 jan 2019

GOOGLE. Como funciona o Content ID. Disponível em < https://support.google.com/youtube/answer/2797370?hl=pt-BR > Acesso em 17 jan 2019. 
ILLING, Sean. Cambridge Analytica, the shady data firm that might be a key Trump-Russia link, explained. 4 abr 2018. Disponível em < https://www.vox.com/policy-andpolitics/2017/10/16/15657512/cambridge-analytica-facebook-alexander-nix-christopher$\underline{\text { wylie }}>$ Acesso em 17 jan 2019

LAIDLAW, Emily B. Online Shaming and the Right to Privacy. Laws 2017. v.6, n.3. 8 fev 2017. doi: https://doi.org/10.3390/laws6010003, Acesso em 17 jan 2019.

MARIZ, Renata. Moro pretende ampliar banco de DNA de criminosos para facilitar investigações. 6 nov 2018. Disponível em < https://oglobo.globo.com/brasil/moro-pretendeampliar-banco-de-dna-de-criminosos-para-facilitar-investigacoes-23215001

MATSUURA, Sérgio. Cuidado: uso excessivo de internet e celular pode viciar. Danos ao cérebro seriam similares aos de drogas como a cocaína. O Globo. 29 jun 2013. Disponível em < https://oglobo.globo.com/sociedade/tecnologia/cuidado-uso-excessivo-de-internetcelular-pode-viciar-8636717 > Acesso em 17 jan 2019

MURARO, Cauê. Chico Buarque retira autorização a 'trabalhos futuros' de Claudio Botelho. 21 mar 2016. Disponível em < http://g1.globo.com/pop-arte/noticia/2016/03/chicobuarque-retira-autorizacao-para-pecas-de-claudio-botelho.html > Acesso 17 jan 2019

NOMOFOBIA: uso excessivo de celular pode levar à ansiedade, tremor e até depressão. R7. 19 jul 2015. Disponível em < http://noticias.r7.com/saude/nomofobia-uso-excessivo-de-

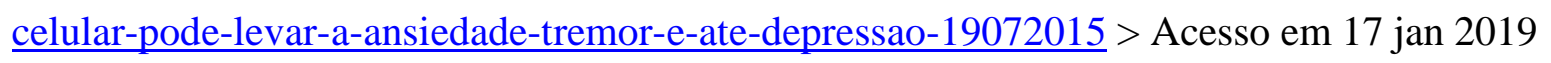

PASSARINHO, Nathalia. Perfil falso na Wikipédia é citado em decisão judicial e trabalho $\begin{array}{llllll}\text { academico. } & 23 & \text { fev } & 2016 . & \text { Disponível em }\end{array}$ http://g1.globo.com/politica/noticia/2016/02/perfil-falso-na-wikipedia-e-citado-emdecisao-judicial-e-trabalho-academico.html > Acesso em 17 jan 2019

PINHO, Débora. Pais vão à Justiça e conseguem registrar filha com nome africano. 9 jan 2001. Disponível em < https://www.conjur.com.br/2001-jan$\underline{\text { 09/justica_autoriza_registro_crianca_nome_africano }}>$ Acesso em 17 jan 2019 
REVISTA FORUM. Pornografia de revanche: em dez dias, duas jovens se suicidam. 21 nov 2013. Disponível em < http://www.revistaforum.com.br/2013/11/21/revenge-porndivulgacao-de-fotos-intimas-culmina-com-suicidio-de-duas-jovens/ Acesso em 17 jan 2019

STIVALETTI, Thiago. Disputa por nomes de sites chega ao país. 28 fev 1999. Disponível em < https://www1.folha.uol.com.br/fsp/cotidian/ff28029925.htm > Acesso em 17 jan 2019

SUWWAN, Leila. Pela primeira vez Justiça autoriza testemunha a trocar sua identidade. 22 ago 2001. Disponível em

https://www1.folha.uol.com.br/fsp/cotidian/ff2208200111.htm $>$ Acesso em 17 jan 2019

WIPO. Domain Name Dispute Resolution Service for Generic Top-Level Domains, disponível em < https://www.wipo.int/amc/en/domains/gtld/ >, Acesso em 17 jan 2019 